\title{
Recent wind-driven variability in Atlantic water mass distribution and
}

\section{meridional overturning circulation}

\author{
Dafydd Gwyn Evans* \\ University of Southampton, National Oceanography Centre Southampton, Southampton, UK. \\ John Toole \\ Woods Hole Oceanographic Institution, Woods Hole, Massachusetts. \\ Gael Forget \\ Massachusetts Institute of Technology, Cambridge, Massachusetts. \\ Jan D. Zika \\ Department of Physics and the Grantham Institute Climate Change and the Environment, \\ Imperial College London, UK. \\ Alberto C. Naveira Garabato \\ University of Southampton, National Oceanography Centre Southampton, Southampton, UK.
}

A. J. George Nurser

Natural Environment Research Council, National Oceanography Centre Southampton, Southampton, $U K$.

Lisan Yu 
${ }_{19}{ }^{*}$ Corresponding author address: Ocean and Earth Sciences, University of Southampton, National 2o Oceanography Centre Southampton, Southampton, UK.

21 E-mail: dafydd.evans@ noc.soton.ac.uk 


\section{ABSTRACT}

Interannual variability in the volumetric water mass distribution within the

${ }_{23}$ North Atlantic subtropical gyre is described in relation to variability in the

${ }_{24}$ Atlantic Meridional Overturning Circulation. The relative roles of diabatic and adiabatic processes in the volume and heat budgets of the subtropical gyre are investigated by projecting data into temperature coordinates as volumes of

${ }_{27}$ water using an Argo based climatology and an ocean state estimate (ECCO v4). This highlights that variations in the subtropical gyre volume budget are predominantly set by transport divergence in the gyre. A strong correlation

30 between the volume anomaly due to transport divergence and the variability of ${ }_{31}$ both thermocline depth and Ekman pumping over the gyre suggests that wind${ }_{32}$ driven heave drives transport anomalies at the gyre boundaries. This windзз driven heaving contributes significantly to variations in the heat content of the ${ }_{34}$ gyre, as do anomalies in the air-sea fluxes. The analysis presented suggests 35 that wind forcing plays an important role in driving interannual variability in ${ }_{36}$ the Atlantic meridional overturning circulation, and that this variability can ${ }_{37}$ be unraveled from spatially-distributed hydrographic observations using the ${ }_{38}$ framework presented here. 


\section{Introduction}

The Atlantic meridional overturning circulation (AMOC) is commonly defined in the depthlatitude plane as the large-scale hemispheric exchange of northward-flowing warm and saline surface waters with compensating southward-flowing cold and fresh deep waters (Talley 2013). The resultant northward heat transport within the North Atlantic affects both the long-term climatic state over northern Europe (Trenberth and Caron 2001; Johns et al. 2010), and the interannual climate variability across the North Atlantic basin (Maidens et al. 2013). This interannual variability can be very pronounced. In 2009-2010 for example, an observational estimate at $26^{\circ} \mathrm{N}$ revealed a temporary reduction in the AMOC strength from a mean of $18.5 \mathrm{~Sv}$ (2004-2009) to 12.8 $\mathrm{Sv}$ between 2009 and mid-2010 ( $\left.1 \mathrm{~Sv}=1 \times 10^{6} \mathrm{~m}^{3} \mathrm{~s}^{-1}\right)$ (McCarthy et al. 2012). It remains unclear whether this change occurred due to local atmospheric forcing anomalies (Roberts et al. 2013; Buckley et al. 2014; Yang 2015), or through remotely forced changes in the overturning (Cunningham et al. 2013; Sonnewald et al. 2013; Bryden et al. 2014).

Understanding the relative roles of atmospheric forcing and intrinsic ocean dynamics in the heat and salt budgets of the North Atlantic Ocean requires a careful separation of many processes that often feed back on each other. The role of the atmosphere is often divided between the long-term impact of buoyancy forcing due to air-sea fluxes of heat and freshwater, and the action of winds on the sea-surface (Polo et al. 2014; Forget and Ponte 2015). The ocean circulation can adjust to the latter on short time scales (hours to months) through barotropic dynamics (Willebrand et al. 1980; Andres et al. 2011, 2012), and on longer timescales (years to decades) through various baroclinic modes (Anderson and Gill 1975; Williams et al. 2013; Forget and Ponte 2015). Both processes affect the ocean by altering its circulation meridionally and zonally. The forced oceanic responses can propagate to remote locations through boundary or Kelvin waves along the equator 
and ocean margins, and through the interior as westward-propagating Rossby waves (Johnson and Marshall 2002; Forget and Ponte 2015). The action of the wind on the sea-surface may also affect circulation changes by driving near surface advection and enhancing near-surface mixing.

Here, we investigate the drivers of interannual AMOC variability as defined and measured using mooring based arrays. We use a water mass analysis framework (Walin 1982; Speer and Forget 2013; Evans et al. 2014; Zika et al. 2015), in which we project data from a gridded Argo product (Roemmich- Gilson Argo climatology: RGAC; Roemmich and Gilson 2009) and an ocean state estimate (Estimating the Circulation and Climate of the Ocean version 4: ECCO v4; Forget et al. 2015a) onto temperature coordinates (Evans et al. 2014). Using this framework, we quantify interannual variations in water mass inventories of the subtropical gyre. The averaging and smoothing required to produce monthly gridded data sets (RGAC and ECCO v4) helps to reduce the impact of aliased variability associated with mesoscale eddies (e.g., see Forget et al. 2011). We then assess the extent to which water mass volume changes are driven by air-sea exchanges of heat (Speer 1993) using various air-sea flux products (ECCO v4, Kalnay et al. 1996; Yu et al. 2006; Dee et al. 2011). We further use ECCO v4 to determine the contributions from lateral transports to water mass inventory changes between $26^{\circ} \mathrm{N}$ and $45^{\circ} \mathrm{N}$ and go on to assess the relationship between those transport variations and perturbations in the wind-stress curl (Dee et al. 2011; Yu and Jin 2014) during the same period.

In this study, we show that interannual AMOC variability at $26^{\circ} \mathrm{N}$ is associated with changes in water mass inventories in the subtropical Atlantic. We describe the data and methods used for this study in section 2 . In sections 3 and 4 , we use the water mass transformation framework to show that the variability in the water mass volume of the subtropical North Atlantic is primarily driven by adiabatic changes in the circulation of the subtropical gyre in response to anomalous windstress curl in the region. However, some fluctuations in heat content anomaly cannot be explained 
entirely by adiabatic processes, but require a diabatic contribution through air-sea fluxes of heat. In section 5 we present evidence that suggests local wind forcing drives much of the observed interannual variability in the AMOC, and discuss the potential for monitoring this variability with basin-scale hydrographic observations.

\section{Data and Methods}

\section{a. Data}

This study uses gridded hydrographic observations, a mooring-based AMOC estimate, a full ocean state estimate and atmospheric reanalyses products to understand the diabatic and adiabatic contributions to water mass variability in the subtropical North Atlantic during the period 2004-2012. From each product we therefore use data between the latitudes of $26^{\circ} \mathrm{N}$ and $45^{\circ} \mathrm{N}$ in the North Atlantic. The gridded hydrographic observations are the Roemmich-Gilson Argo climatology (RGAC; Roemmich and Gilson 2009) accessed at http://sioargo.ucsd.edu/RG_Climatology.html. In this monthly product the temperature and practical salinity data are gridded horizontally using objective analysis on a 1-degree grid and vertically at intervals of $10 \mathrm{~m}$ at the surface increasing to $50 \mathrm{~m}$ at the maximum depth of $1975 \mathrm{~m}$. From these monthly maps we calculate the Conservative Temperature (units $={ }^{\circ} \mathrm{C}$ ) and Absolute Salinity (units $=\mathrm{g} \mathrm{kg}^{-1}$ ) according to TEOS-10 (IOC et al. 2010). To mitigate the effect of water adiabatically heaving across the base of the RGAC domain, our calculation of volume in Conservative Temperature classes only includes water lighter than $\sigma_{0}=27.77\left(\sigma_{0}\right.$ is the potential density anomaly referenced to a sea pressure of 0 dbar) in RGAC. In our domain, this surface is never deeper than $1975 \mathrm{~m}$. This ensures that the measured volume of water does not change due to the heaving of water below the maximum depth of RGAC. Setting this limit using an isopycnal, as opposed to an 
isotherm, is preferable due to the large meridional gradients in Conservative Temperature/Absolute

Salinity along isopycnals within the subtropical North Atlantic. Thus in RGAC, using an isopycnal limit allows colder Conservative Temperature classes that have a lower Absolute Salinity, and thus never heave below $1975 \mathrm{~m}$ to be included.

We also use monthly potential temperature and practical salinity from the Estimating the Circulation and Climate of the Ocean version 4.11 (ECCO v4) state estimate accessed at http://www.eccogroup.org that closely fit Argo data (Forget et al. 2015a). This dataset further provides velocity, transport and surface flux estimates that are dynamically consistent with the estimated hydrography. Throughout, we will refer to Conservative Temperature (from RGAC) and potential temperature (from ECCO v4) as $\Theta$, Absolute Salinity as $S_{A}(\mathrm{RGAC})$ and practical salinity (ECCO v4) as $S$. The interchangeable use of Conservative Temperature and potential temperature introduces a small but negligible error. When using Conservative Temperature and Absolute Salinity we use the equation of state according to TEOS-10. When calculating density from potential temperature and practical salinity we use EOS-80.

We rely on complementary data sets to verify our interpretation of the results. An estimate of the AMOC strength and variability at $26^{\circ} \mathrm{N}$ is obtained from the RAPID-WATCH MOC monitoring project (Smeed et al. 2015). We additionally use monthly mean fields for shortwave radiation, longwave radiation, sensible heat flux and latent heat flux from the NCEP/NCAR (Kalnay et al. 1996) and ERA-interim (Dee et al. 2011) reanalyses to calculate net air-sea heat flux. These have horizontal resolutions of $\sim 1.9^{\circ}$ and $0.75^{\circ}$ respectively. We obtain sea surface temperature (SST; horizontal resolution of $1^{\circ}$ ) from the NOAA optimally interpolated SST product (hereinafter 'Reynolds-SST') as described in Reynolds et al. (2004). For the calculation of windstress curl we use windstress products from the Woods Hole Oceanographic Institution objectively analyzed air- 
sea flux (OAFlux) project (Yu and Jin 2014), calculated using the COARE 3.0 algorithm, which has a horizontal resolution of $0.25^{\circ}$.

The observational estimates used in this study are not all independent of one another. ECCO v4 uses the same Argo temperature and practical salinity data as used in RGAC and takes SST from the Reynolds-SST maps. Further, the first guess atmospheric variables in ECCO v4 were taken from ERA-interim. OAFlux winds use ERA-interim and NCEP/NCAR fields, which includes the scatterometry used in the RAPID-WATCH MOC estimate. ECCO v4 does not use RAPIDWATCH MOC estimates or the underlying Florida Straits transport and scatterometry data. The transport estimates from ECCO v4 and RAPID-WATCH may therefore be considered independent. RGAC can be considered independent from all other estimates used here except for ECCO v4. However, the comparison of observational estimates that are based on very different methodologies, such as ECCO v4 and RGAC, can provide crucial insight into errors that may contaminate such data products.

On the one hand, ECCO v4 estimates include many constraints (observational and dynamical) that can be useful to prevent overfitting to individual datasets, but on the other hand the same constraints may also make it difficult to eliminate widespread misfits completely (several examples are provided in Fig. 10 of Forget et al. 2015a). In this regard it should be noted that ECCO v4 is a greatly improved (albeit surely imperfect) fit to Argo as compared to earlier solutions due to the optimization of turbulent transport parameterizations (see Forget et al. 2015b). RGAC should be expected to closely fit individual Argo profiles since the only other constraint used is an error covariance model. However, this approach is likely more prone to the random errors associated with the irregular sampling of the eddy field by Argo than the ECCO v4 estimate (see Fig. 1 for example). 


\section{b. Calculation of water mass volume and diathermal transformations}

The methods described here are based on the water mass framework of (Walin 1982) applied to a time varying ocean (Evans et al. 2014; Zika et al. 2015). The volume of water within a given $\Theta$ class, delimited by $\Theta^{*} \pm \Delta \Theta / 2$, is given by

$$
V\left(\Theta^{*}, t\right)=\iiint \Pi\left(\Theta, \Theta^{*}\right) \mathrm{d} x \mathrm{~d} y \mathrm{~d} z
$$

where $\Pi$ is a boxcar function that is either 1 when $\Theta(x, y, z, t)$ is within the $\Theta^{*} \pm \Delta \Theta / 2$ range, or otherwise 0 . For simplicity this is written in Cartesian coordinates, but in practice these formula are expressed in spherical polar coordinates. We compute $V$ in the Atlantic between $26^{\circ} \mathrm{N}$ and $45^{\circ} \mathrm{N}$ for each month using a nominal grid spacing $\Delta \Theta$ of $0.5^{\circ} \mathrm{C}$.

The volume, $V$ is set in part by the inflow of water at the boundaries of the domain (e.g. $26^{\circ} \mathrm{N}$ and $\left.45^{\circ} \mathrm{N}\right)$. At latitude $\phi$ the relevant transport is

$$
M_{\phi}\left(\Theta^{*}, t\right)=\iint \Pi\left(\Theta, \Theta^{*}\right) v \mathrm{~d} x \mathrm{~d} z
$$

where $v(x, z, t)$ is the meridional velocity component normal to the domain boundary at latitude $\phi$ (Ferrari and Ferreira 2011; Forget et al. 2011). The volume change set by the divergence of transport across our domain is therefore given by $M=M_{26^{\circ} \mathrm{N}}-M_{45^{\circ} \mathrm{N}}$. This is the adiabatic component of the water mass inventory.

Water mass transformations across surfaces of constant $\Theta$ represent the diabatic contribution to the water mass inventory. These diathermal transformations are the integral of the component of the velocity perpendicular to a given iso-thermal surface. The volume of water being transformed into the $\Theta^{*} \pm \Delta \Theta / 2$ class can be written as $G\left(\Theta^{*}, t\right)=g\left(\Theta^{*}-\Delta \Theta / 2, t\right)-g\left(\Theta^{*}+\Delta \Theta / 2, t\right)$ with

$$
g\left(\Theta^{*}-\Delta \Theta / 2, t\right)=\int_{\Theta^{*}-\Delta \Theta / 2} \frac{1}{|\nabla \Theta|} \frac{\partial \Theta}{\partial t}+\mathbf{u} \cdot \frac{\nabla \Theta}{|\nabla \Theta|} \mathrm{d} A
$$


where $\int_{\Theta^{*}-\Delta \Theta / 2} \mathrm{~d} A$ is the area integral over the isothermal surface where $\Theta(x, y, z, t)=\Theta^{*}-\Delta \Theta / 2$ and $\mathbf{u}(x, y, z, t)$ denotes the three-dimensional velocity field. Equation (3) describes the rate at which water crosses an isotherm from cold to warm. In (3) without mixing processes and/or airsea fluxes that allow $\frac{\partial \Theta}{\partial t}+\mathbf{u} \cdot \nabla \Theta$ to differ from 0 , isothermal surfaces would be impermeable and strictly follow water parcels. The overall budget for $V$ thus is written as

$$
\frac{d V}{d t}=M+G
$$

Practically diagnosing both the adiabatic $(M)$ and diabatic $(G)$ contributions to the water mass inventory change from velocity measurements is difficult. In practice these are therefore determined from changes in the volumetric distribution $V\left(\Theta^{*}, t\right)$. In the case of RGAC, only the net change in $V\left(\Theta^{*}, t\right)$ is readily available. We solve for the monthly transformation rates between temperature classes implied by the monthly $\frac{d V}{d t}\left(\Theta^{*}, t\right)$ by building a series of linear equations to describe the known volume change in each $\Theta$ class in terms of the unknown transformation rates in equation (4) as described in Evans et al. (2014). The results are presented in units of Sverdrups $\left(\mathrm{Sv} ; 1 \mathrm{~Sv}=1 \times 10^{6} \mathrm{~m}^{3} \mathrm{~s}^{-1}\right)$, where a positive transformation implies a shift of $V\left(\Theta^{*}, t\right)$ towards warmer $\Theta$ classes. It should be noted that the results do not necessarily describe the actual path of water through $\Theta$ coordinates (because $M$ may be non zero) but rather the net changes in volumetric distribution (that can be either diabatic or adiabatic in nature). In the case of ECCO v4, $M$ can be determined using the estimated velocity fields (section $2 \mathrm{c}$ ). We thus apply the computational method outlined above to the monthly ECCO v4 estimates of both $d V / d t$ and $M$.

The diathermal transformation $G\left(\Theta^{*}, t\right)$ can be split into contributions due to air-sea heat fluxes $E\left(\Theta^{*}, t\right)$ and mixing $F\left(\Theta^{*}, t\right)$ as

$$
G\left(\Theta^{*}, t\right)=E\left(\Theta^{*}, t\right)+F\left(\Theta^{*}, t\right) .
$$


Using a method similar to Speer (1993), we calculate the rate of water entering the $\Theta^{*} \pm \Delta \Theta / 2$ class due to air-sea heat fluxes as $E\left(\Theta^{*}, t\right)=e\left(\Theta^{*}-\Delta \Theta / 2, t\right)-e\left(\Theta^{*}+\Delta \Theta / 2, t\right)$ with, for example

$$
e\left(\Theta^{*}-\Delta \Theta / 2\right)=\frac{1}{\rho C_{p} \Delta \Theta} \iint \Pi\left(\Theta,\left(\Theta^{*}-\Delta \Theta / 2\right) \pm \Delta \Theta / 2\right) q_{n e t} \mathrm{~d} x \mathrm{~d} y
$$

where $q_{\text {net }}$ is the net surface heat flux $\left(\mathrm{W} \mathrm{m}^{-2}\right), \rho$ is the mean density over the $\Theta^{*}-\Delta \Theta / 2$ isotherm, and $C_{p}$ is the specific heat capacity of seawater. Here, $\Pi$ is a boxcar function that is either 1 when $\Theta(x, y, z, t)$ is within the $\left(\Theta^{*}-\Delta \Theta / 2\right) \pm \Delta \Theta / 2$ range, or otherwise 0 . This computation is carried out using three $q_{\text {net }}$ estimates from NCEP/NCAR, ERA-Interim, and ECCO v4. In NCEP/NCAR and ERA-interim we use Reynolds SST to compute equation (6).

It should be expected that instrumental and sampling errors would affect the volumetric distributions and diathermal transformations calculated as part of this study. Specifically, the aliasing of eddy heave by Argo profiles may increase the error associated with our results. In an attempt to quantify such sampling errors we randomly impose a heave of either $-30 \mathrm{~m}$ or $+30 \mathrm{~m}$ to each grid point and time-step in RGAC, but uniformly to all depths for each grid point. Therefore, a given grid point at $(x, y)$ and a heave of $30 \mathrm{~m}$ for example, $\Theta(x, y, z, t)$ becomes $\Theta(x, y, z+30 m, t)$. We do not decrease the heave to zero at the surface so that if $z+30 m$ is above the sea surface, $\Theta$ is returned to its original value at $0 \mathrm{~m}$. This simple approach serves to illustrate the effect of heave, while only imposing a small bias to the surface $\Theta / S_{A}$ classes. We then re-calculate the water mass volumes and the resulting implied transformations and subtract them from the reference result (Fig. 2). The induced error in water mass volume is an order of magnitude less than the variability in water mass volume (Fig. 2a). The added eddy heave does however generate relatively large variability in the implied month to month transformation rates (Fig. 2b). A similar check using a representative instrumental error for temperature sensors used on $\operatorname{Argo}$ floats $\left(0.002^{\circ} \mathrm{C}\right)$ had a limited impact on 
the calculated water mass volumes and diathermal transformations, giving variations that were 1-2 orders of magnitude smaller than the respective anomalies of these variables.

\section{c. Calculation of the volume change due to the divergence of transport in the subtropical gyre}

We calculate the volume change in $\Theta$ coordinates due to transport changes, $M$, using fields for velocity and Gent-McWilliams (Gent and McWilliams 1990) bolus transport from ECCO v4. The contribution due to resolved sub-monthly variations in velocity and temperature are small in this model and are neglected but would be important at eddy permitting resolution (Doddridge et al. 2016). We consider transects of $\Theta$ and the total meridional transport per grid cell at 26 and $45^{\circ} \mathrm{N}$, and calculate the divergence of the monthly mean transport for each $\Theta$ class. From these changes we then determine the implied volume fluxes between $\Theta$ classes as described above.

Wunsch and Heimbach (2013) show that ECCO v4 simulates well the magnitude and variability of the Eulerian RAPID-WATCH AMOC estimate, although with a slightly reduced range of variability. Here we define the Eulerian overturning circulation in ECCO v4 as the maximum of $\Psi(z, t)=\iint_{z}^{\eta} v d x d z$, where $v$ is the meridional component of velocity and $\eta$ is the sea surface. It is displayed in units of Sv. A comparison of the time-series (Fig. 3) reveals the good agreement between the AMOC estimates with a correlation coefficient of 0.68 through the overlapping period from 2004-2011 (significant at 95\% confidence interval).

Also shown in Fig. 3 is the time-mean (1992-2012) water mass volume change from ECCO v4 within the chosen domain due to the divergence of transports across $26^{\circ} \mathrm{N}$ and $45^{\circ} \mathrm{N}$, and the contribution towards the volume change due to the net transports across the individual sections. These are plotted against $\Theta$ and $S$ to better highlight the contrasting zonal structure of the subtropical gyre (hereinafter 'the gyre') captured by this projection at $26^{\circ} \mathrm{N}$ and $45^{\circ} \mathrm{N}$, providing context for the discussion in the following sections. 
This adiabatic volumetric change implied by the addition/removal of water to our domain by lateral transport across $26^{\circ} \mathrm{N}$ and $45^{\circ} \mathrm{N}$ in ECCO v4 implies the following. At $26^{\circ} \mathrm{N}$, northward transport in the upper ocean, at $\Theta>10^{\circ} \mathrm{C}$, predominantly occurs at the western boundary. Fig. 3(c) shows that waters entering the domain (warm colors) are generally warmer and fresher than the water that leaves the domain (cool colors) as part of the southward recirculation of the gyre. Using the framework described above, if this volume change is used to compute the diathermal volume fluxes from equation (4), this would imply a positive (but adiabatic) volume flux of cold into warm water. At $\Theta<10^{\circ} \mathrm{C}$, deep water leaving the domain imprints as a loss of cold water, also implying a positive volume flux. In contrast, at $45^{\circ} \mathrm{N}$, loss of warmer waters to the north at $\Theta>10^{\circ} \mathrm{C}$ is opposed by a southward transport of cold, deep water at $\Theta<10^{\circ} \mathrm{C}$, thereby inducing an apparent volume flux of warm water into cold water to the south of $45^{\circ} \mathrm{N}$.

\section{d. Calculation of Ekman pumping}

We calculate Ekman pumping as the vertical component of the curl of the wind-stress divided by a reference density $\left(\rho_{0}=1000 \mathrm{~kg} \mathrm{~m}^{-3}\right)$ and $f$, the Coriolis parameter, assuming an ocean at rest. Integrating in time we thus obtain estimates of monthly vertical displacements from OAFlux.

\section{Diabatic and adiabatic contributions to water-mass volume variability in the Subtropical}

$$
\text { Gyre }
$$

First we explore the variability of water mass volume within $\Theta$ classes. A time series of the volumetric distribution in temperature classes highlights both the seasonal variation in the water mass inventory at $\Theta>10^{\circ} \mathrm{C}$ and interannual changes over the entire temperature range (Fig. 4(a) and (b)). In both RGAC (left) and ECCO v4 (right) data, we see a seasonal exchange of volume between the warmer surface waters $\left(\Theta>18^{\circ} \mathrm{C}\right)$ and mode/central waters $\left(\Theta\right.$ between 10 and $\left.18^{\circ} \mathrm{C}\right)$. 
This seasonal variability is imprinted on interannual changes in the water masses with the largest volume: subtropical mode water $\left(\Theta \sim 18^{\circ} \mathrm{C}\right)$, North Atlantic Central Water $\left(\Theta \sim 12^{\circ} \mathrm{C}\right)$ and North Atlantic Deep Water $\left(\Theta \sim 5^{\circ} \mathrm{C}\right)$. It is the diabatic and adiabatic contributions to this interannual variability we aim to characterize. ECCO v4 and RGAC volume anomalies are noticeably different at $\Theta<10^{\circ} \mathrm{C}$. If water denser than $\sigma_{0}=27.7$ are also excluded in $\mathrm{ECCO} v 4$, the two datasets agree more closely. However, excluding water denser than $\sigma_{0}=27.7$ in ECCO v4 does not impact the transformation rates discussed below. During the winter of 2009/10, over a period of 3 months the volume above the permanent thermocline (and depth of maximum overturning; $\Theta>10^{\circ} \mathrm{C}$ ) in both RGAC and ECCO v4 dropped by approximately $2-3 \times 10^{14} \mathrm{~m}^{3}$, equivalent to a transport of $25 \mathrm{~Sv}$. This is indicative of either a diabatic transformation of warm to cold water, or an adiabatic re-arrangement of water masses associated with an export of upper-ocean waters and an import of deep waters across the domain boundaries.

The relative roles of diabatic and adiabatic processes may be assessed by determining the transformation of water between temperature classes required to explain the changes in volume shown in Fig. 4 (a) and (b) (RGAC: Fig. 5 and ECCO v4: Fig. 6). The diabatic contribution to the total change ( $\frac{d V}{d t}$; Fig. 5(a) and 6(a)) is determined using air-sea heat flux products from NCEP/NCAR (E; Fig. 5(b)), ERA-interim (Fig. 5(c) and ECCO v4 (Fig. 6(b)). The adiabatic component of change $(M)$ is inferred from the divergence of lateral transports across $26^{\circ} \mathrm{N}$ and $45^{\circ} \mathrm{N}$ in ECCO v4 (Fig. 6(c)). In all cases positive values indicate cold water being replaced with warm water within the domain of study.

Removing the mean seasonal cycle unveils substantial interannual variability in Figs. 5 and 6. Variability in the anomalous transformations implied by RGAC water mass volume fluctuations are however dominated by noise (Fig. 5). As discussed in section $2 \mathrm{~b}$, this may be a consequence of aliased eddy heave. The remaining time-series, and in particular ECCO v4 (Fig. 6(a)) contain 
anomalously negative signals during the winters of 2009/10 and 2010/11. Such a signal is suggestive of either intensified wintertime cooling or the introduction of excess cold water into our study region across its northern or southern boundaries at those times. Intensified wintertime cooling is consistently seen in water mass transformation rates computed from NCEP/NCAR, ERA-Interim and ECCO v4 surface heat fluxes for temperatures between 15 and $20^{\circ} \mathrm{C}$ (Fig. 5(b)/(c) and Fig. 6(b) respectively). However the adiabatic component (i.e. $M$ ) computed from ECCO v4 (Fig. 6(c)) displays prominent negative anomalies at all temperatures, and in fact explains the bulk of the volumetric census anomalies seen in the winters of $2009 / 10$ and $2010 / 11$ particularly at $\Theta<15^{\circ} \mathrm{C}$ (Fig. 6(a)). The relative contribution of diabatic forcing at $\Theta>15^{\circ} \mathrm{C}$ and adiabatic forcing through all $\Theta$ are consistent throughout the time-series.

Anomalies in the volume of water warmer than $10^{\circ} \mathrm{C}$ can be computed by integrating $\frac{d V^{\prime}}{d t}$ with respect to time and summing over temperature classes according to

$$
\mathbb{V}^{\prime}\left(10^{\circ}, t\right)=\int \sum_{\Theta>10^{\circ}} \frac{d V^{\prime}}{d t} d t
$$

where the 'prime' denotes that the mean seasonal cycle of $\frac{d V}{d t}$ was subtracted. In Fig. 5(d) we compare this volume anomaly computed from $d V^{\prime} / d t$ in RGAC (blue line) to the volume anomaly computed using $E$ from NCEP/NCAR (red dashed) and ERA-interim (magenta dashed). In Fig. 6(d) we compare the volume anomaly computed from $d V^{\prime} / d t$ in ECCO v4 (blue line) to the volume anomaly computed using $M$ in ECCO v4 (cyan line) and volume anomalies computed using $E$ from ECCO v4 (red line), NCEP/NCAR (red dashed) and ERA-interim (magenta dashed). This further highlights the dominant role of the adiabatic term in setting the distribution of volume in $\Theta$ classes within the gyre. The contribution of air-sea heat fluxes to $\mathbb{V}^{\prime}$ at $\Theta>10^{\circ} \mathrm{C}$ will only increase if the domain was extended poleward, beyond the surface outcrop of the $10^{\circ} \mathrm{C}$ isotherm. For control volumes like ours in which the northern boundary mostly lies equatorward 
of the $10^{\circ} \mathrm{C}$ outcrop, air-sea heat fluxes only drive exchange between water mass classes warmer than $10^{\circ} \mathrm{C}$ rather than across the $10^{\circ} \mathrm{C}$ isotherm, so that the total volume warmer than $10^{\circ} \mathrm{C}$ remains unchanged. The RGAC data is again dominated by noise making it difficult to assess the variability shown in Fig. 5(d).

The adiabatic term, driven by the divergence of transport at the boundaries of our domain, can be separated into its components at $26^{\circ} \mathrm{N}$ (cyan long dashed) and $45^{\circ} \mathrm{N}$ (cyan short dashed; Fig. 7(a)) in ECCO v4. The implied volume anomalies evaluated at $\Theta>10^{\circ} \mathrm{C}$ compare well with the AMOC integrated over time in RAPID-WATCH (magenta) and ECCO v4 at $26^{\circ} \mathrm{N}$ (gray long dashed) and $45^{\circ} \mathrm{N}$ (gray short dashed). There are some differences between the RAPID-WATCH volume anomaly and the adiabatic volume term from ECCO v4 (solid cyan), because the latter includes changes due to transport at both $26^{\circ} \mathrm{N}$ and $45^{\circ} \mathrm{N}$. There is also disagreement between the adiabatic volume term based on the transport at $45^{\circ} \mathrm{N}$ (short dashed cyan) and the ECCO v4 overturning at $45^{\circ} \mathrm{N}$ (short dashed gray) during 2009, which is associated with a deepening of the $10^{\circ} \mathrm{C}$ isotherm at the western boundary that is not matched by a change in the depth of maximum $\Psi_{z}$. Importantly the good agreement between the magenta and cyan lines in Fig. 7(a) reveals the importance of the transport variability at $26^{\circ} \mathrm{N}$ in determining the volume budget of the gyre between $26^{\circ} \mathrm{N}$ and $45^{\circ} \mathrm{N}$.

Anomalies in the heat content of water warmer than $10^{\circ} \mathrm{C}$ can then be computed according to

$$
\mathbb{H}^{\prime}\left(10^{\circ}, t\right)=\rho_{0} c_{p} \int \sum_{\Theta>10^{\circ}} \Theta \frac{d V^{\prime}}{d t} d t
$$

where $\rho_{0}$ is a reference density and $c_{p}$ is the (constant) specific heat capacity of water so that $\mathbb{H}^{\prime}$ has units of Joules. Palmer and Haines (2009) demonstrated the value of such an approach to analyze heat content changes using isotherms. The present approach allows the separation of heat content changes due to the adiabatic addition/removal of water at $\Theta>10^{\circ} \mathrm{C}$ and the warming/cooling of 
water at $\Theta>10^{\circ} \mathrm{C}$. Time-series of $\mathbb{H}^{\prime}$ are shown in Fig. 7(b) from the total volume changes in ECCO v4 (blue line), the transport divergence in ECCO v4 (cyan lines) and the air-sea heat fluxes from ECCO v4 (red line), NCEP/NCAR (red dashed) and ERA-interim (magenta dashed). The large dashed and small dashed cyan lines show the contributions to $\mathbb{H}^{\prime}$ in ECCO v4 by transports at $26^{\circ} \mathrm{N}$ and $45^{\circ} \mathrm{N}$ respectively. A negative (positive) slope represents a cooling (warming) in the upper ocean.

In the discussion below all correlations are significant at the $95 \%$ confidence interval during the displayed time-frame of 2004-2012. According to ECCO v4, diabatic air-sea fluxes and adiabatic advection play a roughly equal role in setting the variability of $\mathbb{H}^{\prime}$ with correlations of $r=0.89$ and $r=0.84$ respectively. Variability in transport at $26^{\circ} \mathrm{N}$ correlates more strongly with the adiabatic contribution to $\mathbb{H}^{\prime}(r=0.96)$ than the transport at $45^{\circ} \mathrm{N}(r=0.73)$. Between 2004 and 2012 the standard deviation of the total $\mathbb{H}^{\prime}$ (blue line; $2.9 \times 10^{21} \mathrm{~J}$ ) is mostly determined by the advective term, which has a standard deviation of $1.7 \times 10^{21} \mathrm{~J}$. From equations (4) and (5), differences between the sum of the air-sea flux and advective terms and the total $\mathbb{H}^{\prime}$ allude to the contribution of mixing, but some of this difference may also be due to an insufficient temporal resolution since we use monthly fields in our computations.

The contribution of the adiabatic advective terms in Fig. 6 and Fig. 7 to the negative anomalies during the winters of 2009/10 and 2010/11 suggests that a lateral re-arrangement of water masses across the mid-latitude North Atlantic is related to the abrupt, short-term decline in the AMOC at $26^{\circ} \mathrm{N}$ during these winters. At $26^{\circ} \mathrm{N}$, the negative volume flux anomalies in Fig. 6(a)-(c) and the negative slope of the cyan dashed curve in Fig. 7(a) imply a reduction in the upper-ocean exchange of warm/fresh and cold/salty water driven by the gyre circulation and an increased transport in the deep ocean (Fig. 3 and section $2 \mathrm{c}$ ). At $45^{\circ} \mathrm{N}$, the negative volume flux anomalies in Fig. 6(a)-(c) and the negative slope of the cyan dotted curve in Fig. 7(a) suggest an increase in both 
the northward transport of warm water and/or southward transport of cold water in the winter of $2009 / 2010$. The combination of anomalous transports at $26^{\circ} \mathrm{N}$ and $45^{\circ} \mathrm{N}$ yields an adiabatic volumetric change due to a divergence above the thermocline and a convergence below, consistent with our inferred volumetric changes (Fig. 4) and with the negative anomalies in Fig. 6.

\section{Mechanisms of adiabatic water mass variability during 2009/10 and 2010/11}

The most plausible driver of such a rapid perturbation in the lateral transport through the boundaries of our study region is a change in wind forcing. We consider the relative configuration of the wind-stress and ocean circulation over our region of interest during the winter of 2009/10. Differences exist between the RGAC and ECCO v4 isotherm displacement maps (Figs. 8a and 9a) that may reflect errors in one or both of the estimates. RGAC often shows a checkerboard pattern that we suspect may reflect an aliasing of mesoscale eddy variability (based on Fig. 1 and the overall noisiness of RGAC results). Alternatively, it is possible that ECCO v4 underestimates isothermal shoaling over wide regions between $26^{\circ} \mathrm{N}$ and $45^{\circ} \mathrm{N}$ where it shows lower values than RGAC. However, there is also a general agreement between the two estimates regarding broad patterns of deepening (e.g., in the subpolar gyre, the eastern Atlantic, and over the Gulf Stream) and shoaling (e.g., in the western subtropics and tropics, and along the North Atlantic drift). In particular the overall shoaling seen in both estimates between $26^{\circ} \mathrm{N}$ and $45^{\circ} \mathrm{N}$, which is of most concern to this paper, appears to be a robust feature rather than an artifact due to a particular methodological choice.

During the period of reduced AMOC, a southward shift in the zonal wind-stress maximum (Fig. 8(d)) precedes this shoaling (Figs. 8(c) and 9(b)). Note that the southward shift of the westerlies over the mid-latitude North Atlantic in the winter of 2009/10 was uniquely prolonged during our study period. The southward shift of the wind affects the meridional profile of wind-stress curl, 
generating anomalously positive curl between $35^{\circ} \mathrm{N}$ and $45^{\circ} \mathrm{N}$ and anomalously negative curl between $26^{\circ} \mathrm{N}$ and $35^{\circ} \mathrm{N}$ (Fig. 8(b)). This is consistent with a banded structure in maps of Ekman pumping anomaly and isotherm displacement estimates that is most distinctly seen in Fig. 9a. The changes in isotherm depth and the wind-stress over the subtropical gyre (Figs. 8a and 9a) suggests that the wind-driven gyre circulation shifted south in response to the changing wind field.

During the winter of 2009/10, the change in thermocline depth induced by Ekman pumping implied by the OAFlux wind-stress curl anomaly, averaged between $26^{\circ} \mathrm{N}$ and $45^{\circ} \mathrm{N}$, shows a shoaling similar to the estimated isotherm depth anomalies averaged over the same region (Fig. 8(c) and Fig. 9(b)). In general the agreement between the OAFlux and RGAC derived time-series (black and gray lines in Fig. 8(c)) is poor, with a fairly low correlation coefficient of $r=0.27$, but there is a much better agreement ( $r=0.91$, significant at the 95\% confidence interval) between OAFlux and ECCO v4 isotherm depth change time series (black and gray lines in Fig. 9(b)). Furthermore, the isotherm depth changes implied by variations in vertical velocity at the $10^{\circ} \mathrm{C}$ isotherm (red line; Fig. 9(b)) correlate strongly with isotherm depth changes $(r=0.85)$ and with those implied by variability in Ekman pumping $(r=0.93)$, suggesting our application of Ekman pumping is appropriate here.

Of particular interest are the strong correlations between both the volume and heat content anomaly inferred from the divergence of transport in ECCO v4 (cyan curves in Fig. 7(a) and (b)) and the depth changes due to Ekman pumping $(r=-0.97$ and $r=-0.98$ respectively; black curve in Fig. 9(b)), which suggests that basin-wide variability in wind-stress curl predominantly sets the divergence of upper ocean heat and volume in the gyre. In Fig. 9(b), the volume anomaly due to transport divergence (solid cyan line) has been scaled by the surface area of the $10^{\circ} \mathrm{C}$ isotherm, giving a depth change with a magnitude that matches both the isotherm depth anomaly and depth change implied by Ekman pumping. The causes of the differences between the depth 
change implied by Ekman pumping and the variables represented by the gray, red and cyan lines between 2005 and 2007 are not clear.

\section{Summary and Conclusions}

Our results indicate that interannual fluctuations in the upper ocean $\left(>10^{\circ} \mathrm{C}\right)$ volume budget of the gyre north of $26^{\circ} \mathrm{N}$ are primarily set adiabatically by the variability of meridional transport at $26^{\circ} \mathrm{N}$ and $45^{\circ} \mathrm{N}$, while the diabatic air-sea fluxes have a minimal effect at these time scales. A good agreement between the volume anomaly due to transport divergence and the variability of both thermocline depth and Ekman pumping across the gyre suggests that wind-driven heave plays an important role in the transport anomalies at $26^{\circ} \mathrm{N}$ and $45^{\circ} \mathrm{N}$. Yang (2015) show similar results using a simplified 2-layer model configuration of the North Atlantic. This wind-driven heaving is also a major driver of variations in the heat content of the thermocline waters of the gyre, although anomalies in the air-sea heat fluxes also have an important influence on heat content. While the co-variability of winds and ocean circulation suggests that the wind is driving the ocean, the data is not of high enough temporal resolution to distinguish causality in this ocean/atmosphere mechanism due to the short time-scales on which the ocean responds to this type of wind forcing. Future analysis would therefore require higher temporal resolution data.

Further, we show that a short-term southward shift of the gyre occurred in 2009/10, linked to a southward shift of the westerlies over the North Atlantic basin. This drove an adiabatic shoaling of isotherms through decreased Ekman pumping, presumably leading to transport anomalies across $26^{\circ} \mathrm{N}$ and $45^{\circ} \mathrm{N}$. This suggests that the reduction in the northward transport observed at $26^{\circ} \mathrm{N}$ in 2009/10 (McCarthy et al. 2012; Bryden et al. 2014) reflects a southward shift in the mean structure of the interior gyre circulation. While the shift of the gyre (as delimited by the $10^{\circ} \mathrm{C}$ isotherm) is primarily driven adiabatically, the gyre heat content anomaly is also affected by air-sea heat fluxes. 
We conclude that wind forcing plays an important role in driving local, short-term variations in the AMOC. Wind-driven variability has been shown to impact the AMOC across both the subpolar and subtropical gyres (Häkkinen et al. 2011; Schloesser et al. 2014). Such variations in the AMOC have been shown to have significant climatic impacts over the North Atlantic region (e.g. Cunningham et al. 2013), yet the physical mechanisms of these climatic impacts remain unclear. This short-term AMOC variability is difficult to resolve and understand with direct observational estimates of the overturning, yet may be unraveled by combining transport estimates with broadly distributed hydrographic observations using the analysis framework presented here. We thus propose that this approach could enhance our ability to interpret the causes and implications of the AMOC variability measured with the mooring array at $26^{\circ} \mathrm{N}$.

Acknowledgments. DGE was supported by a Natural Environment Research Council studentship award at the University of Southampton. JMT's contribution was supported by the U.S. National Science Foundation (Grant \#OCE-1332667). GF's contribution was supported by the U.S. National Science Foundation through grant OCE-0961713 and by the U.S. National Oceanic and Atmospheric Administration through grant NA10OAR4310135. The contributions of JDZ and AJGN were supported by the NERC grant Climate scale analysis of air and water masses (NE/K012932/1). ACNG gratefully acknowledges support from the Leverhulme Trust, the Royal Society and the Wolfson Foundation. We also gratefully thank the two anonymous reviewers for their insightful and helpful comments.

\section{References}

Anderson, D. L., and A. Gill, 1975: Spin-up of a stratified ocean, with applications to upwelling. Deep Sea Research and Oceanographic Abstracts, 22 (9), 583 - 596, doi: 
http://dx.doi.org/10.1016/0011-7471(75)90046-7, URL http://www.sciencedirect.com/science/ article/pii/0011747175900467.

Andres, M., Y.-O. Kwon, and J. Yang, 2011: Observations of the kuroshio's barotropic and baroclinic responses to basin-wide wind forcing. Journal of Geophysical Research: Oceans, 116 (C4), n/a-n/a, doi:10.1029/2010JC006863, URL http://dx.doi.org/10.1029/2010JC006863.

Andres, M., J. Yang, and Y.-O. Kwon, 2012: Adjustment of a wind-driven two-layer system with mid-basin topography. Journal of Marine Research, 70 (6), 851-882.

Bryden, H. L., B. A. King, G. D. McCarthy, and E. L. McDonagh, 2014: Impact of a 30\% reduction in atlantic meridional overturning during 2009-2010. Ocean Science Discussions, 11 (2), 789-810, doi:10.5194/osd-11-789-2014, URL http://www.ocean-sci-discuss.net/11/789/2014/.

Buckley, M. W., R. M. Ponte, G. Forget, and P. Heimbach, 2014: Low-frequency SST and upperocean heat content variability in the North Atlantic. Journal of Climate, 27, 4996-5018.

Cunningham, S. A., and Coauthors, 2013: Atlantic meridional overturning circulation slowdown cooled the subtropical ocean. Geophysical Research Letters, 40 (23), 2013GL058 464, doi:10. 1002/2013GL058464, URL http://dx.doi.org/10.1002/2013GL058464.

Dee, D. P., and Coauthors, 2011: The era-interim reanalysis: configuration and performance of the data assimilation system. Quarterly Journal of the Royal Meteorological Society, 137 (656), 553-597, doi:10.1002/qj.828, URL http://dx.doi.org/10.1002/qj.828.

Doddridge, E. W., D. P. Marshall, and A. M. Hogg, 2016: Eddy cancellation of the ekman cell in subtropical gyres. Journal of Physical Oceanography, 46 (10), 2995-3010, doi:10. 1175/JPO-D-16-0097.1, URL http://dx.doi.org/10.1175/JPO-D-16-0097.1, http://dx.doi.org/ 10.1175/JPO-D-16-0097.1. 
Evans, D. G., J. D. Zika, A. C. Naveira Garabato, and A. J. G. Nurser, 2014: The imprint of southern ocean overturning on seasonal water mass variability in drake passage. Journal of Geophysical Research: Oceans, 119 (11), 7987-8010, doi:10.1002/2014JC010097, URL http: //dx.doi.org/10.1002/2014JC010097.

Ferrari, R., and D. Ferreira, 2011: What processes drive the ocean heat transport. Ocean Modelling, 38, 171-186.

Forget, G., J.-M. Campin, P. Heimbach, C. N. Hill, R. M. Ponte, and C. Wunsch, 2015a: Ecco version 4: an integrated framework for non-linear inverse modeling and global ocean state estimation. Geoscientific Model Development Discussions, 8 (5), 3653-3743, doi:10.5194/ gmdd-8-3653-2015, URL http://www.geosci-model-dev-discuss.net/8/3653/2015/.

Forget, G., D. Ferreira, and X. Liang, 2015b: On the observability of turbulent transport rates by argo: supporting evidence from an inversion experiment. Ocean Science, 11 (5), 839-853, doi:10.5194/os-11-839-2015, URL http://www.ocean-sci.net/11/839/2015/.

Forget, G., G. Maze, M. Buckley, and J. Marshall, 2011: Estimated seasonal cycle of north atlantic eighteen degree water volume. Journal of Physical Oceanography, 41 (2), 269-286, doi: 10.1175/2010JPO4257.1, URL http://dx.doi.org/10.1175/2010JPO4257.1, http://dx.doi.org/10. 1175/2010JPO4257.1.

Forget, G., and R. M. Ponte, 2015: The partition of regional sea level variability. Progress in Oceanography, 137, Part A, 173 - 195, doi:http://dx.doi.org/10.1016/j.pocean.2015.06.002, URL http://www.sciencedirect.com/science/article/pii/S0079661115001354.

Gent, P. R., and J. C. McWilliams, 1990: Isopycnal mixing in ocean circulation models. Journal of Physical Oceanography, 20, 150-155. 
Häkkinen, S., P. B. Rhines, and D. L. Worthen, 2011: Warm and saline events embedded in the meridional circulation of the northern north atlantic. Journal of Geophysical Research: Oceans, 116 (C3), n/a-n/a, doi:10.1029/2010JC006275, URL http://dx.doi.org/10.1029/2010JC006275, c03006.

IOC, SCOR, and IAPSO, 2010: The international thermodynamic equation of seawater - 2010: Calculation and use of thermodynamic properties. UNESCO (English), manuals and guides no. 56 ed.

Johns, W. E., and Coauthors, 2010: Continuous, array-based estimates of atlantic ocean heat transport at $26.5^{\circ} \mathrm{n}$. Journal of Climate, 24 (10), 2429-2449, doi:10.1175/2010JCLI3997.1, URL http://dx.doi.org/10.1175/2010JCLI3997.1.

Johnson, H. L., and D. P. Marshall, 2002: A theory for the surface atlantic response to thermohaline variability. J. Phys. Oceanogr., 32, 1121-1132, doi:doi:http://dx.doi.org/10.1175/ 1520-0485(2002)032〈1121:ATFTSA $\rangle 2.0 . C O ; 2$.

Kalnay, E., and Coauthors, 1996: The ncep/ncar 40-year reanalysis project. Bulletin of the American Meterological Society, 77 (3), 437-471, doi:doi:http://dx.doi.org/10.1175/1520-0477(1996) 077〈0437:TNYRP $\rangle$ 2.0.CO;2.

Maidens, A., A. Arribas, A. A. Scaife, C. MacLachlan, D. Peterson, and J. Knight, 2013: The influence of surface forcings on prediction of the north atlantic oscillation regime of winter 2010/11. Monthly Weather Review, 141 (11), 3801-3813, doi:10.1175/MWR-D-13-00033.1, URL http://dx.doi.org/10.1175/MWR-D-13-00033.1.

McCarthy, G., and Coauthors, 2012: Observed interannual variability of the atlantic meridional overturning circulation at $26.5^{\circ} \mathrm{n}$. Geophysical Research Letters, 39 (19), doi:10.1029/ 
2012GL052933, URL http://dx.doi.org/10.1029/2012GL052933.

Palmer, M. D., and K. Haines, 2009: Estimating oceanic heat content change using isotherms. Journal of Climate, 22 (19), 4953-4969, doi:10.1175/2009JCLI2823.1, URL http://dx.doi.org/ 10.1175/2009JCLI2823.1.

Polo, I., J. Robson, R. Sutton, and M. A. Balmaseda, 2014: The importance of wind and buoyancy forcing for the boundary density variations and the geostrophic component of the amoc at $26^{\circ} \mathrm{n}$. Journal of Physical Oceanography, 44 (9), 2387-2408, doi:10.1175/JPO-D-13-0264.1, URL http://dx.doi.org/10.1175/JPO-D-13-0264.1.

Reynolds, R. W., N. A. Rayner, T. M. Smith, D. C. Stokes, and W. Wang, 2004: An Improved In Situ and Satellite SST Analysis for Climate.

Roberts, C. D., and Coauthors, 2013: Atmosphere drives recent interannual variability of the atlantic meridional overturning circulation at $26.5^{\circ} \mathrm{n}$. Geophysical Research Letters, 40 (19), 5164-5170, doi:10.1002/grl.50930, URL http://dx.doi.org/10.1002/grl.50930.

Roemmich, D., and J. Gilson, 2009: The 2004-2008 mean and annual cycle of temperature, salinity, and steric height in the global ocean from the argo program. Progress in Oceanography, 82 (2), 81 - 100, doi:http://dx.doi.org/10.1016/j.pocean.2009.03.004, URL http://www. sciencedirect.com/science/article/pii/S0079661109000160.

Schloesser, F., R. Furue, J. McCreary, and A. Timmermann, 2014: Dynamics of the atlantic meridional overturning circulation. part 2: Forcing by winds and buoyancy. Progress in Oceanography, 120, 154 - 176, doi:http://dx.doi.org/10.1016/j.pocean.2013.08.007, URL http://www.sciencedirect.com/science/article/pii/S0079661113001675. 
Smeed, D., G. McCarthy, D. Rayner, B. Moat, W. Johns, M. Baringer, and C. Meinen, 2015: Atlantic meridional overturning circulation observed by the rapid-mocha-wbts (rapid-meridional overturning circulation and heatflux array-western boundary time series) array at 26n from 2004 to 2014. doi:doi:10.5285/1a774e53-7383-2e9a-e053-6c86abc0d8c7.

Sonnewald, M., J. J.-M. Hirschi, R. Marsh, E. L. McDonagh, and B. A. King, 2013: Atlantic meridional ocean heat transport at 26n: impact on subtropical ocean heat content variability. Ocean Science, 9 (6), 1057-1069, doi:10.5194/os-9-1057-2013, URL http://www.ocean-sci. net/9/1057/2013/.

Speer, K., and G. Forget, 2013: Chapter 9 - global distribution and formation of mode waters. Ocean Circulation and ClimateA 21st Century Perspective, J. G. Gerold Siedler, Stephen M. Griffies, and J. A. Church, Eds., International Geophysics, Vol. 103, Academic Press, 211 - 226, doi:http://dx.doi.org/10.1016/B978-0-12-391851-2.00009-X, URL http://www. sciencedirect.com/science/article/pii/B978012391851200009X.

Speer, K. G., 1993: Conversion among north atlantic surface water types. Tellus, 45, 72-79.

Talley, L. D., 2013: Closure of the global overturing circulation through the indian, pacific, and southern oceans: Schematics and transports. Oceanography, 26 (1), 80-97.

Trenberth, K. E., and J. M. Caron, 2001: Estimates of meridional atmosphere and ocean heat transports. Journal of Climate, 14, 3433-3443.

Walin, G., 1982: On the relation between sea-surface heat flow and thermal circulation in the ocean. Tellus, 34, 187-195.

Willebrand, J., G. H. Philander, and R. C. Pacanowski, 1980: The oceanic response to large-scale atmospheric disturbances. Journal of Physical Oceanography, 10, 411-429. 
Williams, R. G., V. Roussenov, D. Smith, and M. S. Lozier, 2013: Decadal evolution of ocean thermal anomalies in the north atlantic: The effects of ekman, overturning, and horizontal transport. Journal of Climate, 27 (2), 698-719, doi:10.1175/JCLI-D-12-00234.1, URL http://dx.doi.org/10.1175/JCLI-D-12-00234.1.

Wunsch, C., and P. Heimbach, 2013: Two decades of the atlantic meridional overturning circulation: Anatomy, variations, extremes, prediction, and overcoming its limitations. Journal of Climate, 26 (18), 7167-7186, doi:10.1175/JCLI-D-12-00478.1, URL http://dx.doi.org/10. 1175/JCLI-D-12-00478.1.

Yang, J., 2015: Local and remote wind stress forcing of the seasonal variability of the atlantic meridional overturning circulation (amoc) transport at $26.5^{\circ} \mathrm{n}$. Journal of Geophysical Research: Oceans, 120 (4), 2488-2503, doi:10.1002/2014JC010317, URL http://dx.doi.org/10. 1002/2014JC010317.

Yu, L., and X. Jin, 2014: Insights on the oaflux ocean surface vector wind analysis merged from scatterometers and passive microwave radiometers (1987 onward). Journal of Geophysical Research: Oceans, 119 (8), 5244-5269, doi:10.1002/2013JC009648, URL http://dx.doi.org/10. 1002/2013JC009648.

Yu, L., X. Jin, and R. A. Weller, 2006: Role of net surface heat flux in seasonal variations of sea surface temperature in the tropical atlantic ocean. Journal of Climate, 19 (23), 6153-6169, doi:10.1175/JCLI3970.1, URL http://dx.doi.org/10.1175/JCLI3970.1.

Zika, J. D., N. Skliris, A. J. G. Nurser, S. A. Josey, L. Mudryk, F. Laliberté, and R. Marsh, 2015: Maintenance and broadening of the ocean's salinity distribution by the water cycle. Journal of Climate, 28 (24), 9550-9560, doi:10.1175/JCLI-D-15-0273.1, URL http://dx.doi.org/10.1175/ JCLI-D-15-0273.1. 


\section{LIST OF FIGURES}

Fig. 1. Standard deviation of $\left(\Theta_{n+1}^{\prime}-\Theta_{n}^{\prime}\right)$ where $\Theta_{n}^{\prime}$ denotes temperature anomalies from the mean seasonal cycle at month $n$, in Reynolds SST (a), ECCO v4 (b), and RGAC (c). For ECCO v4 and RGAC top panels show the uppermost level whereas panels (d) and (e) show 1500m depth. Note that RGAC shows much larger high-frequency variability than do Reynolds SST or ECCO v4, notably in regions of high eddy activity such as the Gulf stream.

Fig. 2. (a) Black contours represent a time-series of $\log _{10}$ water mass volume (in $\mathrm{m}^{3} /{ }^{\circ} \mathrm{C}$ ) from RGAC with no artificially added error. Colors show the difference between the volume shown by the black contours and the volume calculated with a random vertical heave of either $-30 \mathrm{~m}$ or $+30 \mathrm{~m}$ added to the measurements of $\Theta$. Units are $\mathrm{m}^{3} /{ }^{\circ} \mathrm{C}$. (b) Difference between the diathermal transformations calculated using the volume estimates determined with and without artificially added error. Units: $\mathrm{Sv}\left(1 \mathrm{~Sv}=1 \times 10^{6} \mathrm{~m}^{3} \mathrm{~s}^{-1}\right)$.

Fig. 3. (a) RAPID-WATCH AMOC estimate (red line) and ECCO v4 AMOC at $26^{\circ} \mathrm{N}$. Units: $\mathrm{Sv}(1$ $\mathrm{Sv}=1 \times 10^{6} \mathrm{~m}^{3} \mathrm{~s}^{-1}$ ). (b) Volume change per $\Theta / S$ class due to the time-mean (1992-2012) transport per $\Theta / S$ class at $26^{\circ} \mathrm{N}$ minus time-mean transport per $\Theta / S$ at $45^{\circ} \mathrm{N}$ from ECCO v4. Units: $\mathrm{m}^{3} /{ }^{\circ} \mathrm{C}$ psu. (c) Volume change per $\Theta / S$ class due to the time-mean (1992-2012) transport per $\Theta / S$ class at $26^{\circ} \mathrm{N}$ from ECCO v4. Units: $\mathrm{m}^{3} /{ }^{\circ} \mathrm{C} / \mathrm{psu}$. (d) As in (c) but for transport per $\Theta / S$ class at $45^{\circ} \mathrm{N}$.

Fig. 4. (a) Volume anomaly in $\Theta$ classes with respect to the time-mean for the period shown from RGAC in the North Atlantic between 26 and $45^{\circ} \mathrm{N}$. Units are $\mathrm{m}^{3} /{ }^{\circ} \mathrm{C}$. (b) As (a) but for ECCO v4.

Fig. 5. (a) Total monthly $\frac{d V}{d t}$ (see equation (4)) from RGAC between $26^{\circ} \mathrm{N}$ and $45^{\circ} \mathrm{N}$. The mean (2004-2012) seasonal cycle has been removed. (b) Monthly diathermal transformation due to air-sea heat fluxes ( $E$; equation (6)) from NCEP/NCAR air-sea heat fluxes using Reynolds-SST between $26^{\circ} \mathrm{N}$ and $45^{\circ} \mathrm{N}$. The mean (2004-2012) seasonal cycle has been removed. (c) As in (b) but using ERA-Interim air-sea heat fluxes. Units: $\mathrm{Sv}\left(1 \mathrm{~Sv}=1 \times 10^{6}\right.$ $\left.\mathrm{m}^{3} \mathrm{~s}^{-1}\right)$. (d) Volume anomaly $\left(\mathbb{V}^{\prime}\right.$; equation (7)) for temperatures greater than $10^{\circ} \mathrm{C}$. Units: $\mathrm{m}^{3}$.

Fig. 6. (a) Total monthly $\frac{d V}{d t}$ (see equation (4)) from ECCO v4 between $26^{\circ} \mathrm{N}$ and $45^{\circ} \mathrm{N}$. The mean (2004-2012) seasonal cycle has been removed. (b) Monthly diathermal transformation due to air-sea heat fluxes ( $E$; equation (6)) from ECCO v4 between $26^{\circ} \mathrm{N}$ and $45^{\circ} \mathrm{N}$. The mean (2004-2012) seasonal cycle has been removed. (c) Transformation implied by the volume change per $\Theta$ class due to monthly variations in the transport per $\Theta$ class at $26^{\circ} \mathrm{N}$ minus the volume change per $\Theta$ class due to monthly variations in the transport at $45^{\circ} \mathrm{N}$, from ECCO v4 (i.e. $M$ from equation (4)). The mean (2004-2012) seasonal cycle has been removed. Units: $\mathrm{Sv}\left(1 \mathrm{~Sv}=1 \times 10^{6} \mathrm{~m}^{3} \mathrm{~s}^{-1}\right)$. (d) Volume anomaly $\left(\mathbb{V}^{\prime}\right.$; equation (7)) for temperatures greater than $10^{\circ} \mathrm{C}$. Units: $\mathrm{m}^{3}$.

Fig. 7. (a) AMOC monthly-mean anomaly (2004-2012), estimated from RAPID-WATCH (magenta line). Volume anomaly $\left(\mathbb{V}^{\prime}\right.$; equation (7)) for temperatures greater than $10^{\circ} \mathrm{C}$ calculated using $M$ (cyan line), $M_{26^{\circ} \mathrm{N}}$ (cyan-dashed) and $M_{45^{\circ} \mathrm{N}}$ (cyan-dotted). Time integrated AMOC monthly-mean anomaly (2004-2012) from ECCO v4 (i.e. $\Psi_{z}$ ) at $26^{\circ} \mathrm{N}$ and $45^{\circ} \mathrm{N}$ (dashed and dotted gray lines respectively). Units: $\mathrm{m}^{3}$. (b) Implied heat content anomaly ( $\mathbb{H}^{\prime}$ from equation (8)) at $\Theta>10^{\circ} \mathrm{C}$ from the monthly $\frac{d V}{d t}$ from ECCO v4 (blue line), $E$ from ECCO v4 (red line), $M$ from ECCO v4 (cyan line), $M_{26^{\circ} \mathrm{N}}$ from ECCO v4 (cyan-dashed), $M_{45^{\circ} \mathrm{N}}$ from ECCO v4 (cyan-dotted), $E$ from NCEP/NCAR (black dotted) and $E$ from ERA-Interim (magenta dotted). Units: J. 
Fig. 8. (a) Colors represent depth anomaly (with respect to the monthly-mean for 2004-2012) of the $10^{\circ} \mathrm{C}$ isotherm from RGAC, averaged over May 2010 to November 2010. Red indicates a shoaling and blue indicates a deepening. Units: $\mathrm{m}$. Solid contours indicate the zero iso-line of the wintertime-mean (2004-2008) zonal wind-stress (units: $\mathrm{N} \mathrm{m}^{-2}$ ) and dotted contours show the zero iso-line of the zonal wind-stress averaged over November 2009 to March 2010 from OAFlux. (b) Zonal mean wind-stress curl averaged over the same time periods from OAFlux. Units: $\mathrm{N} \mathrm{m}^{-3}$. (c) Depth anomaly (with respect to the monthly-mean for 20042012) of the $10^{\circ} \mathrm{C}$ isotherm averaged over 26 and $45^{\circ} \mathrm{N}$ from RGAC (gray). Time-integrated vertical Ekman velocity anomaly (with respect to the monthly-mean for 2004-2012) from OAFlux (black). Time-integrated vertical velocity anomaly (with respect to the monthlymean for 2004-2012) at the $10^{\circ} \mathrm{C}$ isotherm from ECCO v4 (red). Units: m. (d) Latitude of maximum zonal wind-stress with monthly-mean removed. Units: Degrees.

Fig. 9. (a) Colors represent isotherm depth anomaly from ECCO v4 as in Fig. 8(a). Contours show the difference in the time-accumulated vertical Ekman velocity anomaly (with respect to the monthly-mean for 2004-2012) between the periods averaged over May 2009 to November 2009 and May 2010 to November 2010 from OAFlux. The solid (dotted) contour shows the (-) $2.5 \times 10^{-6} \mathrm{~ms}^{-1}$ isosurface. (b) Depth anomaly (with respect to the monthly-mean for 2004-2012) of the $10^{\circ} \mathrm{C}$ isotherm averaged over 26 and $45^{\circ} \mathrm{N}$ from ECCO v4 (gray). Timeintegrated vertical Ekman velocity anomaly (with respect to the monthly-mean for 20042012) from OAFlux (black). Time-integrated vertical velocity anomaly (with respect to the monthly-mean for 2004-2012) at the $10^{\circ} \mathrm{C}$ isotherm from ECCO v4 (red). Volume anomaly $\left(\mathbb{V}^{\prime}\right)$ from ECCO v4 transport divergence (from Fig. 7(a)) scaled by the surface area of the $10^{\circ} \mathrm{C}$ isotherm (cyan). Units: $\mathrm{m}$. Dashed lines correspond to the similarly colored solid lines of heat content anomaly $\left(\mathbb{H}^{\prime}\right)$ shown in Fig. 7(b). 

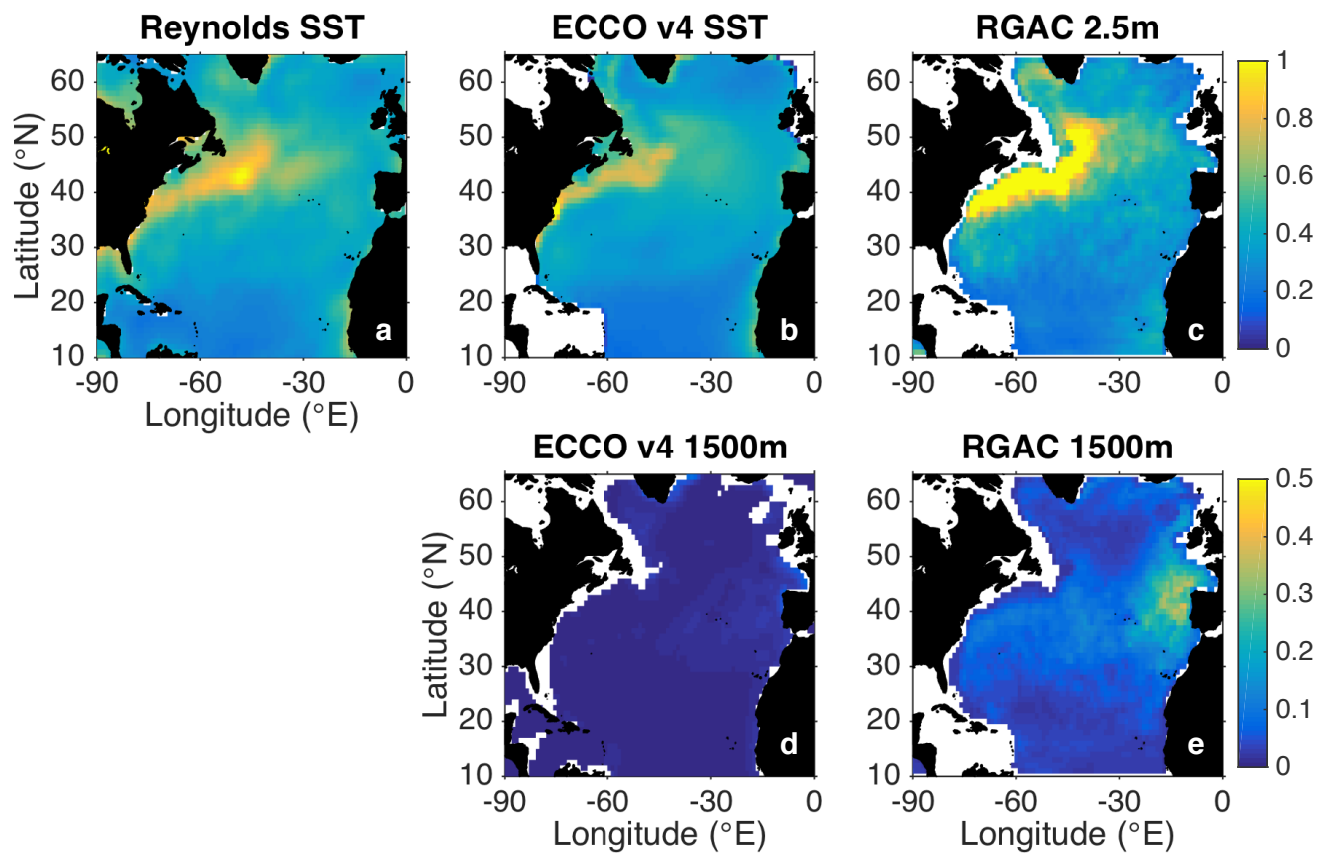

FIG. 1. Standard deviation of $\left(\Theta_{n+1}^{\prime}-\Theta_{n}^{\prime}\right)$ where $\Theta_{n}^{\prime}$ denotes temperature anomalies from the mean seasonal cycle at month $n$, in Reynolds SST (a), ECCO v4 (b), and RGAC (c). For ECCO v4 and RGAC top panels show the uppermost level whereas panels (d) and (e) show 1500m depth. Note that RGAC shows much larger high-frequency variability than do Reynolds SST or ECCO v4, notably in regions of high eddy activity such as the Gulf stream. 

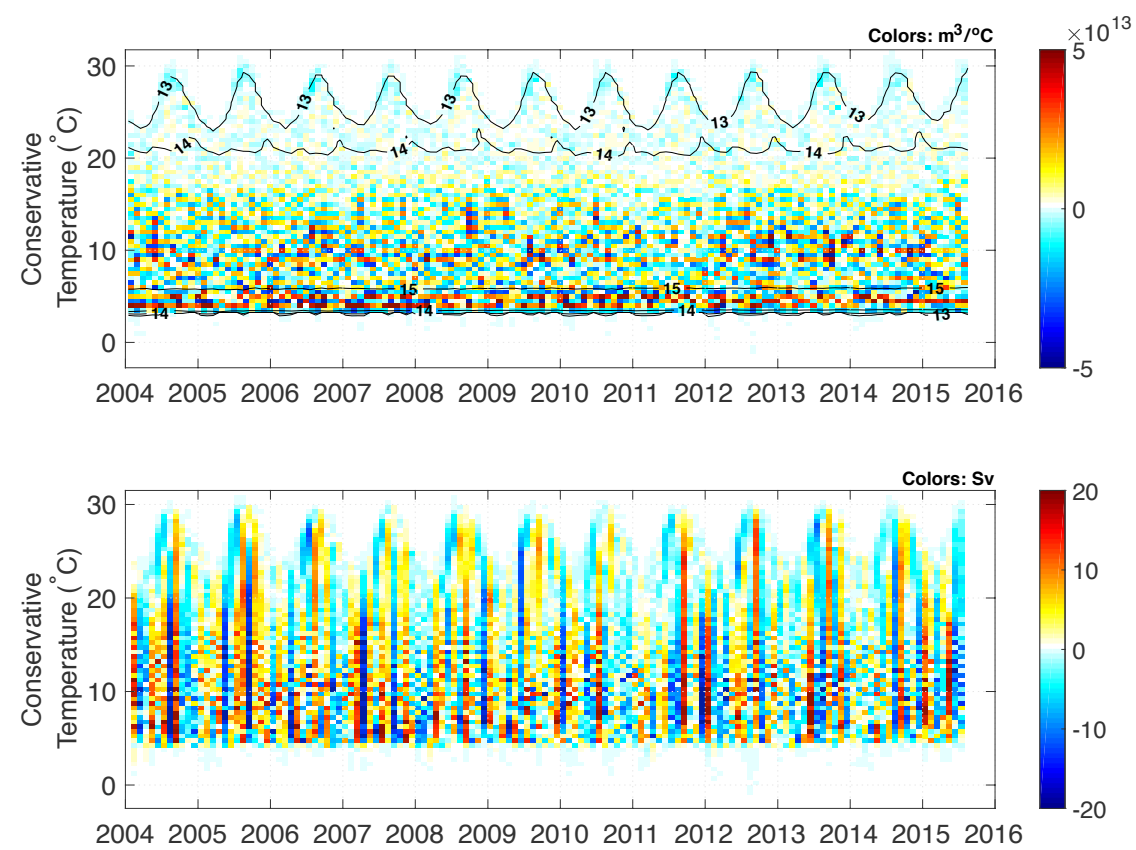

FIG. 2. (a) Black contours represent a time-series of $\log _{10}$ water mass volume (in $\mathrm{m}^{3} /{ }^{\circ} \mathrm{C}$ ) from $\mathrm{RGAC}$ with

no artificially added error. Colors show the difference between the volume shown by the black contours and the volume calculated with a random vertical heave of either $-30 \mathrm{~m}$ or $+30 \mathrm{~m}$ added to the measurements of $\Theta$. Units are $\mathrm{m}^{3} /{ }^{\circ} \mathrm{C}$. (b) Difference between the diathermal transformations calculated using the volume estimates determined with and without artificially added error. Units: $\mathrm{Sv}\left(1 \mathrm{~Sv}=1 \times 10^{6} \mathrm{~m}^{3} \mathrm{~s}^{-1}\right)$. 



FIG. 3. (a) RAPID-WATCH AMOC estimate (red line) and ECCO v4 AMOC at $26^{\circ}$ N. Units: $\mathrm{Sv}(1 \mathrm{~Sv}=$ $\left.1 \times 10^{6} \mathrm{~m}^{3} \mathrm{~s}^{-1}\right)$. (b) Volume change per $\Theta / S$ class due to the time-mean (1992-2012) transport per $\Theta / S$ class at $26^{\circ} \mathrm{N}$ minus time-mean transport per $\Theta / S$ at $45^{\circ} \mathrm{N}$ from ECCO v4. Units: $\mathrm{m}^{3} /{ }^{\circ} \mathrm{C}$ psu. (c) Volume change per $\Theta / S$ class due to the time-mean (1992-2012) transport per $\Theta / S$ class at $26^{\circ} \mathrm{N}$ from ECCO v4. Units: $\mathrm{m}^{3} /{ }^{\circ} \mathrm{C} / \mathrm{psu}$. (d) As in (c) but for transport per $\Theta / S$ class at $45^{\circ} \mathrm{N}$. 



FIG. 4. (a) Volume anomaly in $\Theta$ classes with respect to the time-mean for the period shown from RGAC in

C. (b) As (a) but for ECCO v4. 


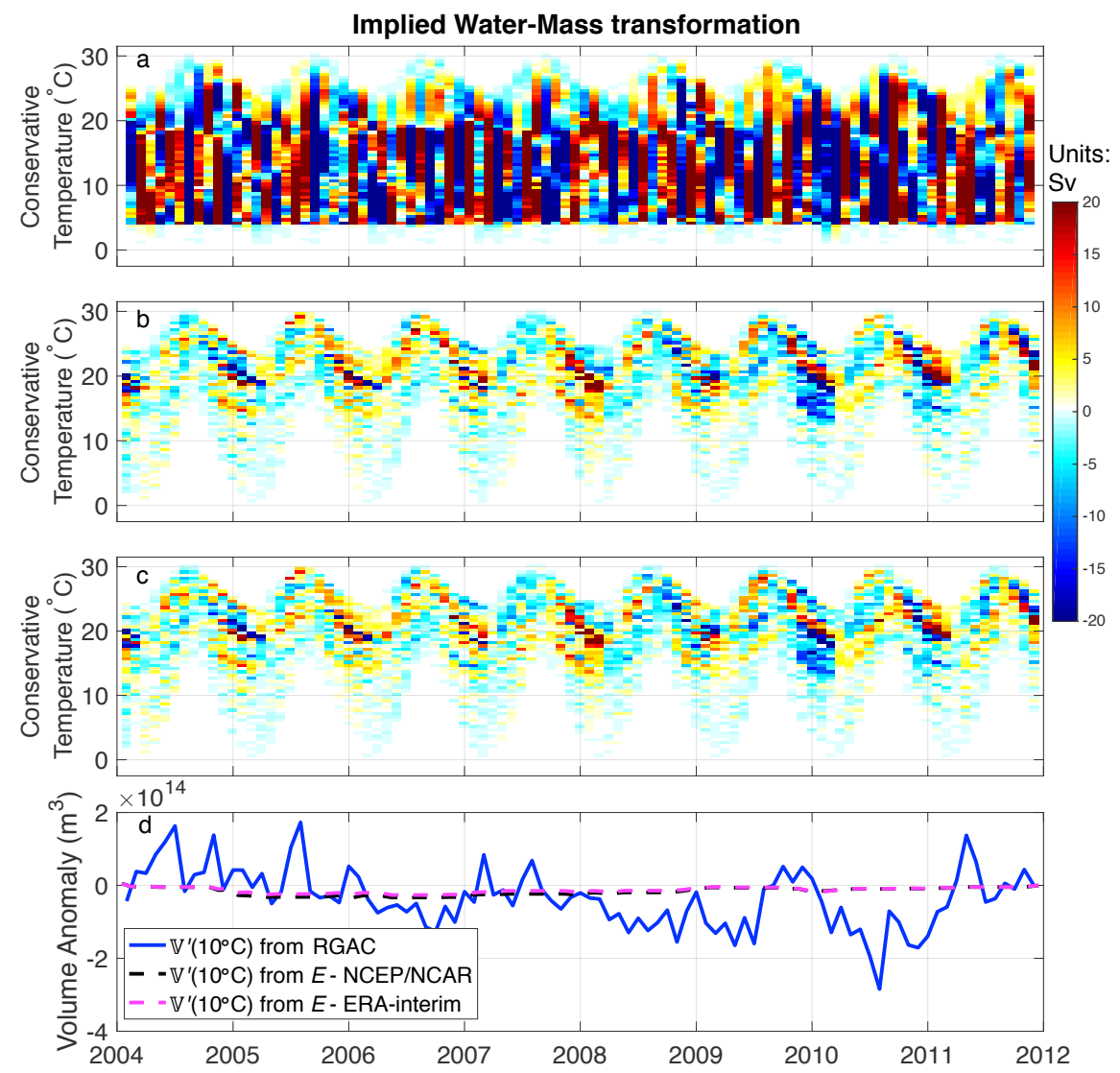

FIG. 5. (a) Total monthly $\frac{d V}{d t}$ (see equation (4)) from RGAC between $26^{\circ} \mathrm{N}$ and $45^{\circ} \mathrm{N}$. The mean (2004-2012) seasonal cycle has been removed. (b) Monthly diathermal transformation due to air-sea heat fluxes ( $E$; equation (6)) from NCEP/NCAR air-sea heat fluxes using Reynolds-SST between $26^{\circ} \mathrm{N}$ and $45^{\circ} \mathrm{N}$. The mean (20042012) seasonal cycle has been removed. (c) As in (b) but using ERA-Interim air-sea heat fluxes. Units: Sv (1 $\left.\mathrm{Sv}=1 \times 10^{6} \mathrm{~m}^{3} \mathrm{~s}^{-1}\right)$. (d) Volume anomaly $\left(\mathbb{V}^{\prime}\right.$; equation (7)) for temperatures greater than $10^{\circ} \mathrm{C}$. Units: $\mathrm{m}^{3}$. 


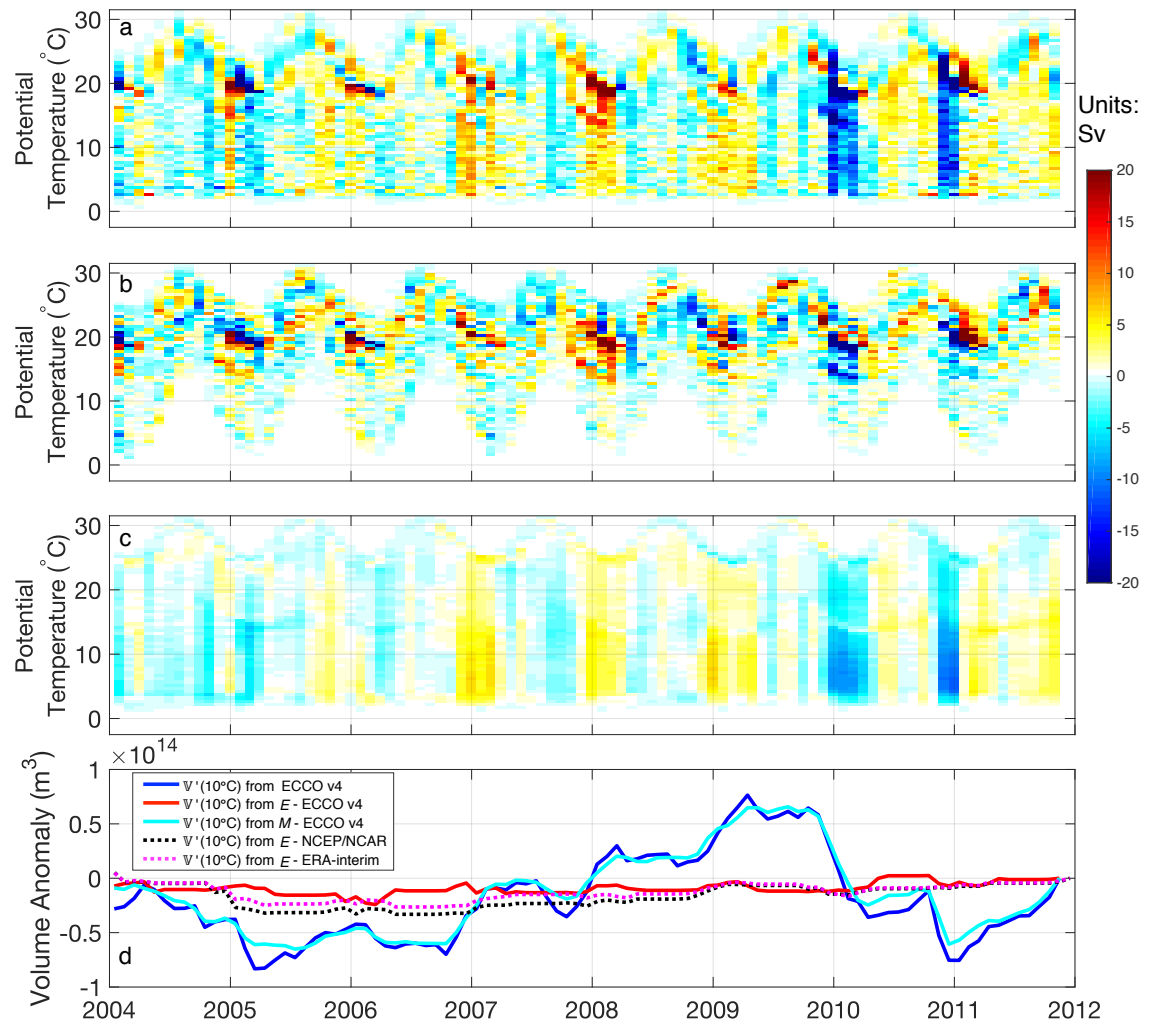

FIG. 6. (a) Total monthly $\frac{d V}{d t}$ (see equation (4)) from ECCO v4 between $26^{\circ} \mathrm{N}$ and $45^{\circ} \mathrm{N}$. The mean (20042012) seasonal cycle has been removed. (b) Monthly diathermal transformation due to air-sea heat fluxes $(E$; equation (6)) from ECCO v4 between $26^{\circ} \mathrm{N}$ and $45^{\circ} \mathrm{N}$. The mean (2004-2012) seasonal cycle has been removed. (c) Transformation implied by the volume change per $\Theta$ class due to monthly variations in the transport per $\Theta$ class at $26^{\circ} \mathrm{N}$ minus the volume change per $\Theta$ class due to monthly variations in the transport at $45^{\circ} \mathrm{N}$, from ECCO v4 (i.e. $M$ from equation (4)). The mean (2004-2012) seasonal cycle has been removed. Units: Sv (1 $\left.\mathrm{Sv}=1 \times 10^{6} \mathrm{~m}^{3} \mathrm{~s}^{-1}\right)$. (d) Volume anomaly $\left(\mathbb{V}^{\prime}\right.$; equation (7)) for temperatures greater than $10^{\circ} \mathrm{C}$. Units: $\mathrm{m}^{3}$. 


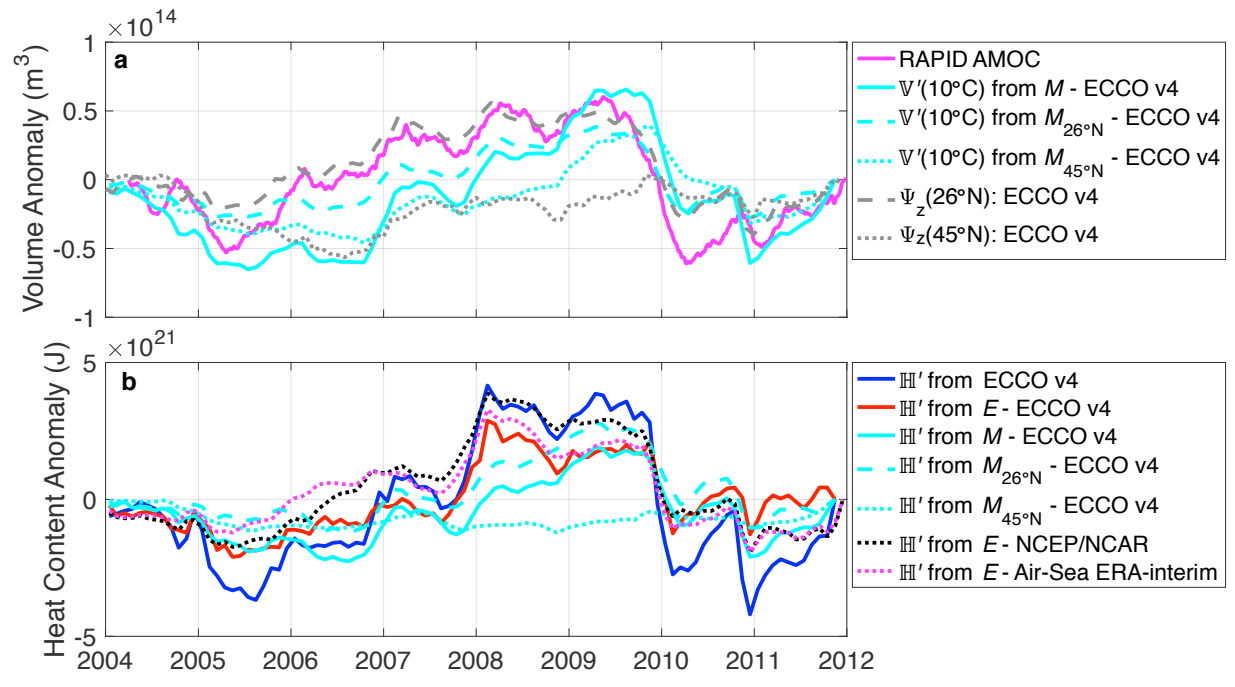

FIG. 7. (a) AMOC monthly-mean anomaly (2004-2012), estimated from RAPID-WATCH (magenta line).

Volume anomaly $\left(\mathbb{V}^{\prime}\right.$; equation (7)) for temperatures greater than $10^{\circ} \mathrm{C}$ calculated using $M$ (cyan line), $M_{26^{\circ} \mathrm{N}}$ (cyan-dashed) and $M_{45^{\circ} \mathrm{N}}$ (cyan-dotted). Time integrated AMOC monthly-mean anomaly (2004-2012) from ECCO v4 (i.e. $\Psi_{z}$ ) at $26^{\circ} \mathrm{N}$ and $45^{\circ} \mathrm{N}$ (dashed and dotted gray lines respectively). Units: $\mathrm{m}^{3}$. (b) Implied heat content anomaly ( $\left(\mathbb{H}^{\prime}\right.$ from equation (8)) at $\Theta>10^{\circ} \mathrm{C}$ from the monthly $\frac{d V}{d t}$ from ECCO v4 (blue line), $E$ from ECCO v4 (red line), $M$ from ECCO v4 (cyan line), $M_{26^{\circ} \mathrm{N}}$ from ECCO v4 (cyan-dashed), $M_{45^{\circ} \mathrm{N}}$ from ECCO v4 (cyan-dotted), $E$ from NCEP/NCAR (black dotted) and $E$ from ERA-Interim (magenta dotted). Units: J. 

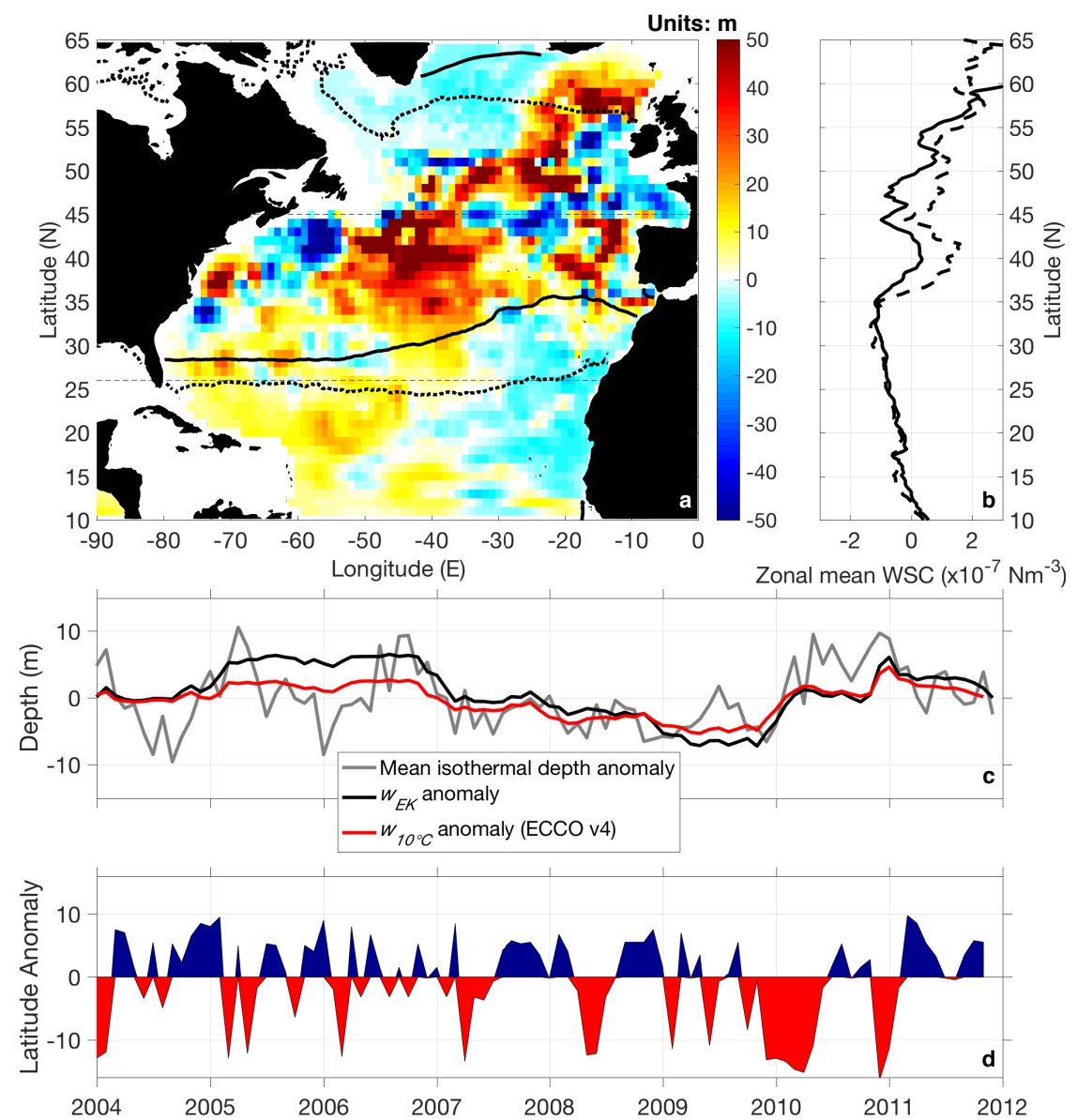

FIG. 8. (a) Colors represent depth anomaly (with respect to the monthly-mean for 2004-2012) of the $10^{\circ} \mathrm{C}$ isotherm from RGAC, averaged over May 2010 to November 2010. Red indicates a shoaling and blue indicates a deepening. Units: m. Solid contours indicate the zero iso-line of the wintertime-mean (2004-2008) zonal wind-stress (units: $\mathrm{N} \mathrm{m}^{-2}$ ) and dotted contours show the zero iso-line of the zonal wind-stress averaged over November 2009 to March 2010 from OAFlux. (b) Zonal mean wind-stress curl averaged over the same time periods from OAFlux. Units: $\mathrm{N} \mathrm{m}^{-3}$. (c) Depth anomaly (with respect to the monthly-mean for 2004-2012) of the $10^{\circ} \mathrm{C}$ isotherm averaged over 26 and $45^{\circ} \mathrm{N}$ from RGAC (gray). Time-integrated vertical Ekman velocity anomaly (with respect to the monthly-mean for 2004-2012) from OAFlux (black). Time-integrated vertical velocity anomaly (with respect to the monthly-mean for 2004-2012) at the $10^{\circ} \mathrm{C}$ isotherm from ECCO v4 (red). Units: m. (d) Latitude of maximum zonal wind-stress with monthly-mean removed. Units: Degrees. 

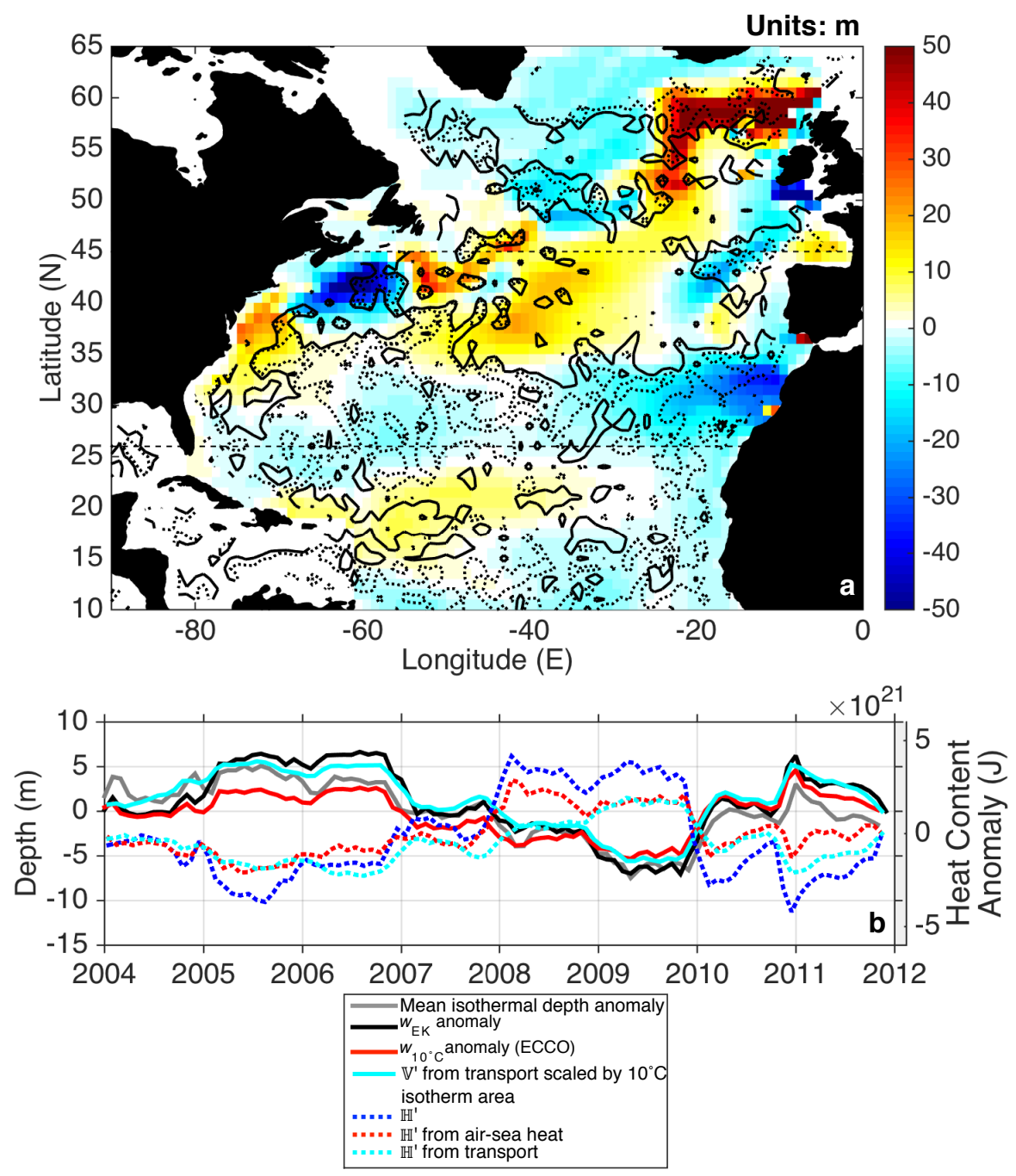

FIG. 9. (a) Colors represent isotherm depth anomaly from ECCO v4 as in Fig. 8(a). Contours show the difference in the time-accumulated vertical Ekman velocity anomaly (with respect to the monthly-mean for 2004-2012) between the periods averaged over May 2009 to November 2009 and May 2010 to November 2010 from OAFlux. The solid (dotted) contour shows the $(-) 2.5 \times 10^{-6} \mathrm{~ms}^{-1}$ isosurface. (b) Depth anomaly (with respect to the monthly-mean for 2004-2012) of the $10^{\circ} \mathrm{C}$ isotherm averaged over 26 and $45^{\circ} \mathrm{N}$ from ECCO v4 (gray). Time-integrated vertical Ekman velocity anomaly (with respect to the monthly-mean for 2004-2012) from OAFlux (black). Time-integrated vertical velocity anomaly (with respect to the monthly-mean for 20042012) at the $10^{\circ} \mathrm{C}$ isotherm from ECCO v4 (red). Volume anomaly ( $\left.\mathbb{V}^{\prime}\right)$ from ECCO v4 transport divergence (from Fig. $7(\mathrm{a})$ ) scaled by the surface area of the $10^{\circ} \mathrm{C}$ isotherm (cyan). Units: m. Dashed lines correspond to the similarly colored solid lines of heat content anomaly $\left(\mathbb{H}^{\prime}\right)$ shown in Fig. 7(b). 